\title{
Assessing the performance of hospitals before and after the implementation of Iran's Health Sector Evolution Plan (HSEP) using the Pabon Lasso model
}

\author{
Rohaneh Rahimisadegh ${ }^{1}$, Ali Akbar Haghdoost ${ }^{2}$, Samira Emadi ${ }^{1}$, Somayeh Noori Hekmat* ${ }^{3}$ (D) \\ Received: 12 Jun 2019 \\ Published: 15 Feb 2021
}

\section{Abstract}

Background: The health sector evolution plan was implemented in 2014 in government hospitals across the country as a part of the universal health coverage achievement programs. This study assessed the performance of hospitals before and after the implementation of this plan, using the Pabon Lasso model.

Methods: The population of this study consisted of the hospitals of the country in the 2013-2015 time frame; overall, 874 hospitals (94.5\% of the population) were included in the study. In order to assess performance, we used the Pabon Lasso model and hospital performance indicators (Average Length of Stay, Bed Turnover, and Bed Occupancy Rate). The data were collected from the Hospital Information System and provincial deputies of curative affairs and were then analyzed using the descriptive indicators of mean, frequency, and median in SPSS 22. Also, Paired Student T-test and ANOVA were used to compare the performance of different groups of hospitals before and after the implementation of the health sector evolution plan.

Results: The implementation of the health sector evolution plan has led to a significant improvement in the three performance indicators in the hospitals of the country. Before the implementation of the health sector evolution plan, the most inefficient, inefficient, fairly efficient, and most efficient zones included $31 \%, 18 \%, 17 \%$, and $33 \%$ of the studied hospitals, respectively. However, the implementation of the health sector evolution plan changed the percentages to $29 \%, 21 \%, 20 \%$, and $30 \%$, respectively. Teaching hospitals, which are governmental and are mostly located in capital cities of the provinces, were overall more inefficient than non-teaching hospitals.

Conclusion: The number of the most efficient and most inefficient hospitals has decreased, and the number of average performance hospitals has increased after the implementation of the health sector evolution plan. Therefore, the health sector evolution plan has not led to an overall increase or decrease in the performance of hospitals but has reduced the difference in the performance of hospitals. Equal support of government hospitals along with financial protection against health expenses, improves the performance indicators of hospitals and reduces performance differences among them.

Keywords: Average length of stay, Bed occupancy rate, Bed turnover, Teaching hospital, Health Sector Evolution Plan, Iran

\author{
Conflicts of Interest: None declared \\ Funding: None \\ *This work has been published under CC BY-NC-SA 1.0 license. \\ Copyright $\odot$ Iran University of Medical Sciences
}

Cite this article as: Rahimisadegh R, Haghdoost AA, Emadi S, Noori Hekmat S. Assessing the performance of hospitals before and after the implementation of Iran's Health Sector Evolution Plan (HSEP) using the Pabon Lasso model. Med J Islam Repub Iran. 2021 (15 Feb);35:23. https://doi.org/10.47176/mjiri.35.23

\section{Corresponding author: Dr Somayeh Noori Hekmat, snhekmat@kmu.ac.ir}

1. Health Services Management Research Center, Institute for Futures Studies in Health, Kerman University of Medical Sciences, Kerman, Iran

2. Health Modeling Research Center, Institute for Futures Studies in Health, Kerman University of Medical Sciences, Kerman, Iran

3. Management and Leadership in Medical Education Research Center, Kerman University of Medical Sciences. Kerman, Iran

\section{$\uparrow$ What is "already known" in this topic:}

The government hospitals, which are generally teaching hospitals, have better situation than other types of hospitals, such as public, private, charity hospitals that are non- teaching, in terms of performance indicators such as bed occupancy rate (BOR), bed turnover (BTO) and average length of stay (ALS).

\section{$\rightarrow$ What this article adds:}

This study showed that the Health Sector Evolution Plan has increased performance indicators in both government and nongovernment hospitals in Iran. Also, this plan through creating similar policies and strategies in government hospitals, has caused some most efficient and most inefficient hospitals to become hospitals with moderate performance. 


\section{Introduction}

In most countries, hospitals are the foundation of health service provision, simultaneously monitoring and regulating the other health service provider organizations in their catchment area (1) and their function has a great impact on the success of the health system (2) .In Iran, more than $80 \%$ of hospitals are public, with private and charity hospitals constituting the other $20 \%$ (3). Public government hospitals have the highest share in satisfying the medical needs of the society, but in recent years, due to financing problems, people's access to hospital services has become increasingly limited, with nearly $17 \%$ of people lacking health insurance in 2010 (4). According to the report issued by the Eastern Mediterranean Regional Office (EMRO) of WHO in Iran, the Out of Pocket share of the total health expenses was $58 \%$, and various reports have claimed that between $8.3 \%$ and $22.2 \%$ of the Iranian households have faced heavy health expenses (5).

The aforementioned issues show that the goals of the health sector, as defined in the fifth socio-economic development program, have not been achieved. Therefore, in the new government, special attention was paid to the health sector, and both the Parliament and the government provided the required resources for the reformation of the health system. The health evolution plan was implemented in 2014 in government hospitals (affiliated with MOHME) of Iran, aiming at providing financial protection for patients, improving justice in access to health services, and improving the quality of health services (6). Based on this plan, hospital service coinsurance is $5 \%$ of the total expenses for rural patients and $10 \%$ for urban patients; all medicines and medical equipment necessary for hospitalized patients are provided free of charge, and extensive services are provided to support patients with severe illnesses. The plan was based on the presupposition that considering the prior lack of patient financial protection, a dramatic reduction in hospitalization and treatment expenses in government hospitals should lead to an increase in the utilization of the hospital facilities and significant changes in their performance. However, there is no evidence on the national level to prove or reject this hypothesis.

The Health Sector Evolution Plan was implemented only in government hospitals, but because both government and non-government hospitals are parts of a health system, so despite the implementation of this plan in government hospitals, there are indirect effects on non-government hospitals in the country. Therefore, in this study, the effects of the implementation of this plan on all hospitals in the country were examined.

Several models have been designed for the assessment of organization performance, among which Pabon Lasso is specially designed to assess hospital performance (7). In this model, three performance indicators of bed occupancy rate (BOR), bed turnover (BTO), and the average length of stay (ALS) are analyzed in order to assess the overall performance of hospitals (8). In the Pabon Lasso graphic model, four sectors are constructed by two indicators of BOR (longitudinal axis X) and BTO (lateral axis Y). In order to check the validity of the graph, a line is drawn to connect zero to the point representing each hospital and projected to reach the point representing the ALS value of that hospital (9).

So far, many studies have employed this technique to assess the performance of hospitals in Iran (10-15) and other countries (16-22), but fiew have analyzed the performance of all of the hospitals in a country using this model. In this study, we analyzed the impact of HSEP on the performance of hospitals classified according to their main characteristics, such as type, size, and location, using the PL method.

\section{Methods}

The present study is a descriptive-analytical study which is conducted cross-sectionally. In this study, the Pabon Lasso model was used to analyze the data related to the performance indicators of all of the hospitals in the country.

\section{Study Population}

The population included 924 hospitals that were operational between 2013 and 2015 in Iran. As the records of some hospitals were either not available or not properly reported, 874 hospitals $(94.5 \%)$ were included in the study. These 874 hospitals included government hospitals, public quasi-government hospitals (army and social security affiliated), private hospitals, and charity hospitals. It is worth mentioning that the health sector evolution plan was implemented only in government and university hospitals, which are affiliated with MOHME.

\section{Data Source}

The data related to the performance indicators (bed occupancy rate, average length of stay, and bed turnover) of hospitals between 2013 and 2015 were collected from the Hospital Information System. Data related to the number of beds, type of ownership, city, and population of the city in which hospitals were collected by the research team of the deputy of curative affairs of all provinces across the country. In order to collect information, an exclusive data portal was designed, and data related to hospitals in each of the 439 counties were entered into the portal by an expert in the deputy of curative affairs of each province. The data were sent to the research team after confirmation by the provincial authorities.

\section{Data Analysis}

The performance of hospitals was assessed using the Pabon Lasso model in this study. The Pabon Lasso model is one of the most important and suitable methods for assessing hospital performance (18). In this model, the performance of hospitals is assessed using performance indicators of bed occupancy rate (BOR), average length of stay (ALS), and bed turnover (BTO) $(19,23)$.

In order to draw the Pabon Lasso graphic diagram, a vertical and a horizontal line were drawn at the medians of BOR and BTO, creating four quadrants (zones) in the 
graph $(17,19)$. BOR medians for hospitals were 63 and 70 , in 2013 (before the HSEP) and in 2015 (after the implementation of HSEP), respectively. Also, BTO medians for hospitals were 82 and 92 in 2013 and 2015, respectively. Pabon Lasso graphs were designed based on these values in SPSS 22.

Later on, the data related to the performance indicators were entered into SPSS 22, and the location of each hospital on the Pabon Lasso graph was determined using the Regression Variable Plots command. Also, separate graphs were designed based on parameters such as function, ownership, and city in order to achieve a better representation of the locations of hospitals on the graphs in the years before and after the implementation of HSEP. Consequently, each hospital was placed in one quadrant based on its performance indicator values. The position of each hospital in each quadrant shows the efficiency status of that hospital $(22,24)$.

In order to compare the status of performance indicators of different groups of hospitals in the years before and after the implementation of HSEP, Paired Student t-test and ANOVA test were used.

\section{Results}

Accurate information on the performance indicators of 874 hospitals out of a total of 924 hospitals in Iran was available and was included in the study. Analysis of findings showed that the means of the three indicators of bed occupancy rate, average length of stay, and bed turnover increased after the implementation of HSEP and that the increase was significant (Table 1).

In the three years altogether, $27 \%$ of government hospitals were placed in the first zone, $22 \%$ in the second and fourth zones, and $30 \%$ in the third zone. Also, on average, $35 \%$ of non-government hospitals were placed in the third zone and $33 \%$ in the first zone.

Based on the performance division in the Pabon Lasso model, before the implementation of HSEP, $31 \%$ of hospitals were in the most inefficient zone, $18 \%$ in the inefficient zone, $33 \%$ in the most efficient zone, and $17 \%$ in the efficient zone; however, after the implementation of HSEP, $29 \%$ were in the most inefficient zone, $21 \%$ in the inefficient zone, $30 \%$ in the most efficient zone, and $20 \%$ in the efficient zone.

Table 1. The average of hospital performance indicators in Iran by type of hospital from 2013 to 2015

\begin{tabular}{|c|c|c|c|c|c|c|c|c|c|c|c|c|}
\hline \multicolumn{2}{|c|}{ Hospital type } & \multirow[t]{2}{*}{ Number } & \multirow[t]{2}{*}{ Percent } & \multicolumn{2}{|c|}{ BOR } & \multirow[t]{2}{*}{$\mathrm{p}^{*}$} & \multicolumn{2}{|c|}{ ALS } & \multirow[t]{2}{*}{$\mathrm{p}^{*}$} & \multicolumn{2}{|c|}{ BTO } & \multirow[t]{2}{*}{$\mathrm{p} *$} \\
\hline & & & & Before & After & & Before & After & & Before & After & \\
\hline \multirow{5}{*}{ Ownership } & Government $^{1}$ & 552 & $63 \%$ & 59.46 & 69.68 & $<0.001$ & 3.28 & 3.42 & 0.037 & 81.50 & 98.84 & $<0.001$ \\
\hline & Public $^{2}$ & 137 & $16 \%$ & 63.47 & 66.15 & 0.080 & 4.21 & 4.36 & 0.4010 & 85.49 & 86.94 & 0.640 \\
\hline & Private & 156 & $18 \%$ & 50.21 & 56.23 & $<0.001$ & 2.33 & 2.67 & 0.001 & 88.89 & 99.14 & 0.005 \\
\hline & Charity & 29 & $3 \%$ & 51.45 & 56.00 & 0.030 & 2.03 & 2.27 & 0.0810 & 89.97 & 94.07 & 0.540 \\
\hline & $\mathrm{p} *$ & & & $<0.001$ & $<0.001$ & & $<0.001$ & 0.001 & & 0.330 & 0.340 & \\
\hline \multirow{3}{*}{ Type } & Teaching & 265 & $30 \%$ & 68.37 & 76.02 & $<0.001$ & 4.33 & 4.37 & 0.7210 & 80.51 & 90.90 & $<0.001$ \\
\hline & Non- teaching & 609 & $70 \%$ & 53.74 & 62.03 & $<0.001$ & 2.73 & 2.96 & $<0.001$ & 85.12 & 99.47 & $<0.001$ \\
\hline & $\mathrm{p}^{*}$ & & & $<0.001$ & $<0.001$ & & $<0.001$ & $<0.001$ & & 0.200 & 0.100 & \\
\hline \multirow{9}{*}{ Size } & $\begin{array}{c}\text { Fewer than } 32 \\
\text { beds }\end{array}$ & 100 & $11 \%$ & 32.64 & 44.25 & $<0.001$ & 1.87 & 2.35 & 0.025 & 67.60 & 99.91 & 0.053 \\
\hline & $33-64$ & 180 & $21 \%$ & 49.38 & 57.61 & $<0.001$ & 2.83 & 3.01 & 0.013 & 83.42 & 97.63 & $<0.001$ \\
\hline & $65-100$ & 158 & $18 \%$ & 56.23 & 64.85 & $<0.001$ & 3.19 & 3.39 & 0.1310 & 85.88 & 96.73 & 0.001 \\
\hline & $101-180$ & 263 & $30 \%$ & 67.30 & 74.15 & $<0.001$ & 3.21 & 3.26 & 0.2110 & 94.28 & 103.78 & $<0.001$ \\
\hline & $181-250$ & 81 & $9 \%$ & 65.94 & 73.54 & $<0.001$ & 3.73 & 3.84 & 0.1910 & 78.86 & 88.21 & 0.003 \\
\hline & $251-400$ & 57 & $7 \%$ & 74.32 & 80.42 & $<0.001$ & 4.78 & 4.67 & 0.5310 & 78.49 & 86.47 & $<0.001$ \\
\hline & $401-600$ & 22 & $3 \%$ & 72.73 & 81.41 & 0.030 & 6.77 & 7.59 & 0.4910 & 57.77 & 63.82 & 0.004 \\
\hline & More than & 12 & $1 \%$ & 78.75 & 81.75 & 0.240 & 4.00 & 4.00 & 1.0010 & 75.25 & 78.83 & 0.190 \\
\hline & $\begin{array}{r}600 \text { beds } \\
\text { p* }\end{array}$ & & & $<0.001$ & $<0.001$ & & $<0.001$ & $<0.001$ & & $<0.001$ & 0.150 & \\
\hline \multirow{3}{*}{ Location } & Provincial $^{3}$ & 480 & $55 \%$ & 62.22 & 67.73 & $<0.001$ & 3.81 & 3.96 & 0.068 & 82.93 & 90.35 & $<0.001$ \\
\hline & District $^{4}$ & 394 & $45 \%$ & 53.27 & 64.49 & $<0.001$ & 2.50 & 2.70 & $<0.001$ & 84.70 & 104.82 & $<0.001$ \\
\hline & $\mathrm{p}^{*}$ & & & $<0.001$ & 0.022 & & $<0.001$ & $<0.001$ & & 0.600 & 0.003 & \\
\hline \multirow{9}{*}{$\begin{array}{l}\text { Population } \\
\text { of the city }\end{array}$} & $\begin{array}{l}\text { Under } 50000 \\
\text { population }\end{array}$ & 55 & 100 & 33.20 & 49.55 & $<0.001$ & 1.94 & 2.33 & 0.001 & 57.87 & 83.73 & $<0.001$ \\
\hline & $50000-100000$ & 99 & $11 \%$ & 48.91 & 62.32 & $<0.001$ & 2.13 & 2.36 & 0.024 & 85.05 & 105.30 & $<0.001$ \\
\hline & $100000-300000$ & 199 & $23 \%$ & 57.98 & 67.58 & $<0.001$ & 2.46 & 2.56 & 0.158 & 88.59 & 110.65 & 0.006 \\
\hline & $300000-500000$ & 91 & $11 \%$ & 63.32 & 70.14 & $<0.001$ & 4.02 & 3.99 & 0.750 & 86.60 & 96.64 & 0.015 \\
\hline & $500000-1000000$ & 108 & $12 \%$ & 60.04 & 69.45 & $<0.001$ & 3.84 & 4.29 & 0.002 & 77.67 & 87.59 & 0.011 \\
\hline & $\begin{array}{l}1000000- \\
2000000\end{array}$ & 149 & $17 \%$ & 63.00 & 67.80 & $<0.001$ & 3.83 & 3.87 & 0.590 & 86.21 & 95.61 & $<0.001$ \\
\hline & Over 2000000 & 173 & $20 \%$ & 63.68 & 67.00 & 0.007 & 3.80 & 3.98 & 0.330 & 85.71 & 87.38 & 0.490 \\
\hline & $\mathrm{p}^{*}$ & & & $<0.001$ & $<0.001$ & & $<0.001$ & $<0.001$ & & 0.003 & 0.015 & \\
\hline & Total & 874 & $100 \%$ & 58.18 & 66.27 & $<0.001$ & 3.22 & 3.39 & 0.001 & 83.73 & 96.87 & $<0.001$ \\
\hline
\end{tabular}

${ }^{1}$ Government hospitals include MOHME affiliated hospitals which are established and managed using government budget.

${ }^{2}$ Public quasi-government hospitals are hospitals which are established by military organizations, banks, large industries, and social security insurance and provide free services or services with government prices.

${ }^{3}$ Hospitals located in capitals of provinces.

${ }^{4}$ Hospitals located in districts outside capital cities. 
The mean of performance of hospitals in the three-year span shows that $30 \%$ of hospitals were in the first (most inefficient) zone, and $31 \%$ were in the third (most efficient) zone of the Pabon Lasso graph. Public quasigovernment, private, charity, non-teaching, district, and small (under 180 beds) hospitals as well as hospitals located in cities with populations under 300 thousand people, had a higher share in the two aforementioned groups.

Also, 19\% of hospitals were in the second and fourth zones of the graph, among which government, public quasi-government, private, teaching, provincial, and over180-bed hospitals, as well as hospitals located in cities with populations over 500 thousand, had a higher share in these two groups (Graph 1).

Graph 1 demonstrates the mean of performance for hospitals related to each category in the years between 2013 and 2015. This column graph demonstrates the percentage of the hospitals in each performance status to the total hospitals in each category.

If the green column is high, it means that there are more hospitals with good performance, and the red column means poor performance. This graph shows that the green part (the share of efficient hospitals of the total hospitals in the category) in the group of teaching, government, and provincial hospitals includes fewer hospitals than the other groups do. Therefore, it seems that the performance of non-government, non-teaching, district, and small hospitals, as well as hospitals located in small cities, is better.

Graph 2 clearly demonstrates the effect of the implementation of HSEP on the performance of hospitals in the country. Graph 2 is a reflective graph that demonstrates the movement of hospitals among the zones of the Pabon Lasso graph between 2013 and 2015. As observed, the combined number of hospitals is the same in the two lower zones and the two upper zones. The lower area demon- strates the number of hospitals that left the performance zone after the implementation of HSEP and the upper area shows the number of hospitals that were transferred to a new zone after the implementation of HSEP.

In this graph, when the red part (the number of hospitals with poor performance) is in the upper area of the graph, it means that after the implementation of HSEP, the performance of some hospitals has declined, and the size of the red part shows the percentage of changes; the bigger the red part is, the higher the percentage of efficient and fairly efficient hospitals that became inefficient after the implementation of HSEP becomes

If the green part is in the upper area of the graph, it means that the HSEP has made some hospitals more efficient. The bigger this green part is, the higher the percentage of poor and average performance hospitals that have become efficient due to HSEP becomes. Based on these guidelines, considering the fact that in most categories, the green and red parts are below the origin axis, we can say that between 2013 and 2015, the number of most efficient and most inefficient hospitals decreased and that the performance of most hospitals moved toward the average. The only cases of performance improvement are seen in hospitals with 400 to 600 beds and in hospitals with 180 to 25 beds.

In this graph, the length of the columns shows the percentage of hospitals that experienced changes in performance leading to a place shift on the Pabon Lasso graph after the implementation of HSEP. The hospitals with more than 600 beds experienced the greatest changes in performance after the implementation of HSEP, and hospitals with 181 to 250 beds experienced the smallest change in performance.

In Graph 2, the low height of the columns for most categories shows that very limited changes occurred in them,

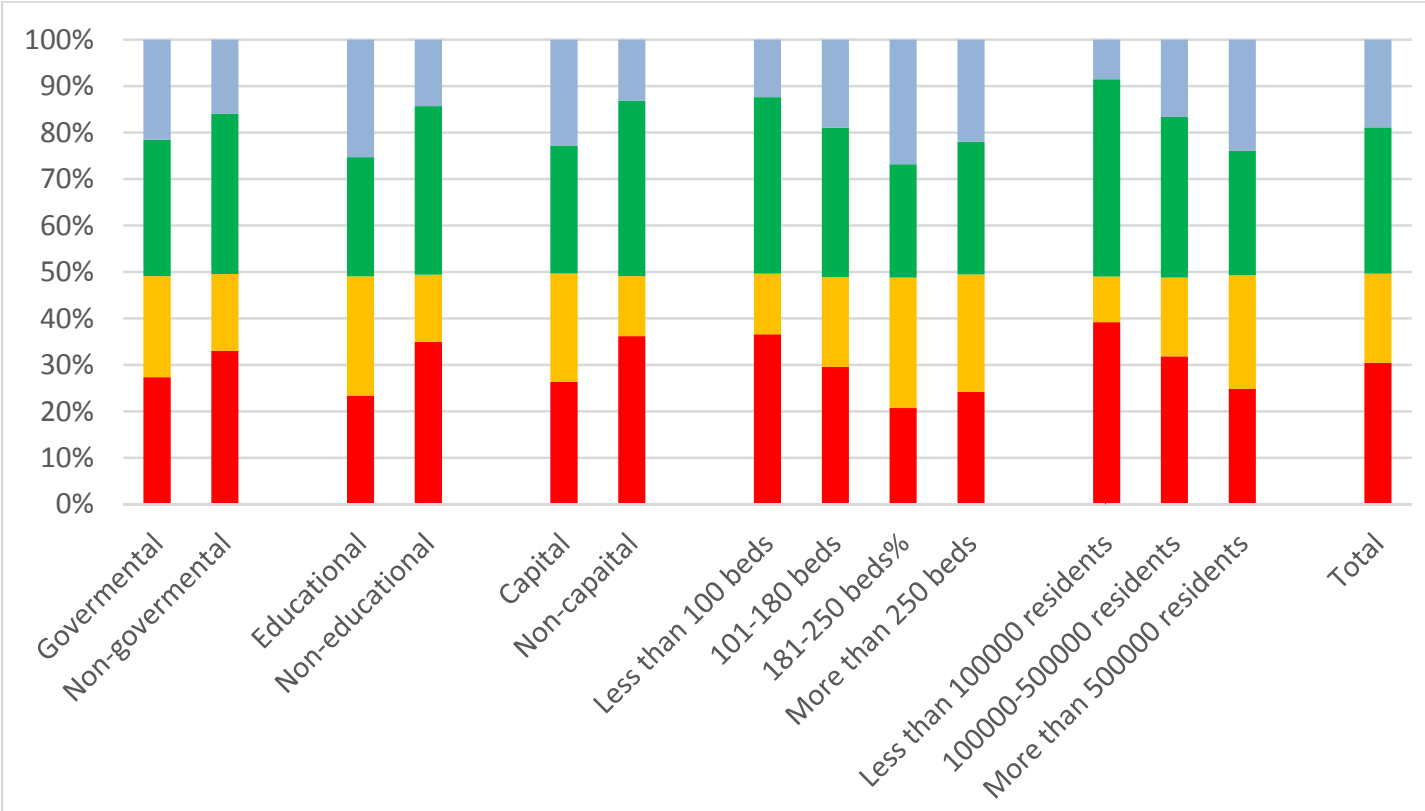

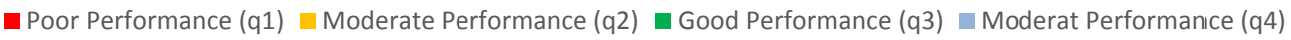




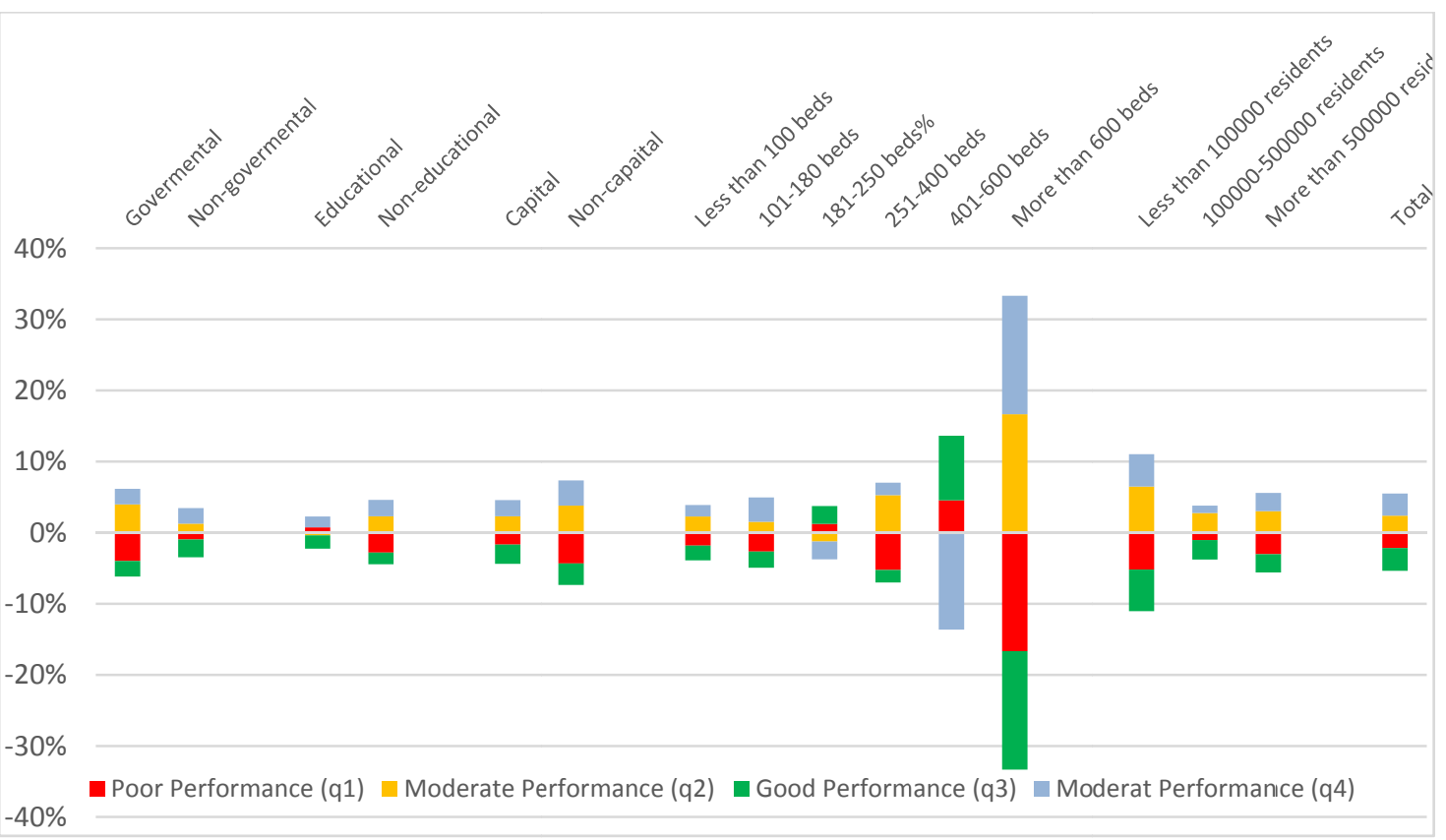

Graph 2. The effect of the HSEP on the performance of hospitals of the country (changes occurred in 2013-2015)

and that less than $10 \%$ of the hospitals experienced movement between the zones of the Pabon Lasso graph. Only in the category of hospitals with 401 to 600 beds and hospitals with more than 600 beds, more than $10 \%$ of hospitals moved from one zone to another. For instance, in total, less than $5 \%$ of non-government hospitals and less than $3 \%$ of teaching hospitals moved from one zone to another during the three-year span of the study. On the other hand, the height of all the data points on the graph for hospitals with more than 600 beds shows that after the implementation of HSEP, these hospitals have experienced great change in their performance and that $17 \%$ of hospitals with good performance and $17 \%$ of hospitals with poor performance have achieved an average performance level.

\section{Discussion}

The present study was conducted aiming at assessing the performance of hospitals of Iran before and after the implementation of the health sector evolution plan (HSEP) using the Pabon Lasso model.

Most hospitals in Iran are governmental, and therefore, most of the programs for achieving Universal Health Coverage (UHC) are implemented in these hospitals (24-26). The HSEP was the most important intervention which affected the hospitals in the time span of the study, and it was only implemented in government hospitals (27). Therefore, we may attribute the increase in performance indicators to the implementation of this plan. The significant decrease in the patient share of expenses in government hospitals was the most important outcome of the HSEP, which led to the sudden rush of a large number of patients toward government hospitals. Accumulation of unmet health needs in recent years was the main reason for the sudden increase in the bed occupancy rate in government hospitals in 2015. Also, providing much cheaper diagnostic and therapeutic services in government hospitals (patient's share of health expenses was 5-10\%) for all patients has caused poorer patients and those who needed more complicated treatments and longer stays to choose government hospitals (28).

Increases in indicators in non-government hospitals can be due to the reactions of these hospitals and the population to the implementation of HSEP in government hospitals. The fact that government hospitals are crowded and their capacity is always full, and efforts of private, charity, and public hospitals for improving the utilization of hospital beds can be reasons for an increase in non-government hospital performance indicators in the years after the implementation of HSEP $(29,30)$. Findings of other studies which were related to the assessment of the changes due to the implementation of HSEP also showed that the high number of patients using government hospitals and the long waiting lists have caused some of the remaining patients to choose non-government hospitals; thus, probably with the increase in the bed occupancy rate in government hospitals, the value of this indicator increased in nongovernment hospitals as well (31).

Some of the findings of the study are different from the findings of other studies. In most cases, teaching hospitals in large cities are introduced as efficient hospitals (32-34). Also, findings of an extensive study on 371 urban hospitals for acute care in America showed that teaching hospitals have better performance than non-teaching hospitals (35). However, the findings of the present study showed that teaching hospitals in Iran had a lower performance 
than non-teaching hospitals. It seems that two factors may account for this issue. First, in the logic of the Pabon Lasso model, an increase in the average length of stay and consequently a decrease in the bed turnover rate will cause the hospitals to be placed in fairly inefficient and inefficient zones. The advocates of this logic believe that long stays will not lead to the improvement of the treatment outcomes but will prevent the utilization of hospital beds for other patients (36-38). In addition, we need to consider the fact that teaching hospitals are referral destinations for patients with chronic and complex disease from small cities (39). Therefore, in these hospitals, the average length of stay is higher, and bed turnover is lower than they are in other hospitals, which will in turn, place them among inefficient hospitals $(6,40,41)$.

The second reason for the low performance of teaching hospitals could be related to their nature and role in the medical sciences education system. In 1985 in Iran, medical sciences research and education were integrated with the Ministry of Health. Consequently, all of the government hospitals in large cities became teaching hospitals (42). Teaching hospitals have various functions such as treatment of patients, educating students, and conducting research projects (43). In fact, curing patients (with educational aims) along with promises by the government to satisfy all the medical needs of people and to support patients with low income have exposed teaching hospitals to inefficiency $(44,45)$. Also, similar findings showed the inefficiency of teaching hospitals in the Czech Republic (40).

The findings of the present study showed that as the hospital size increases, the average length of stay would significantly rise and the average length of stay in hospitals with 400 to 600 beds is nearly 3 times higher than hospitals with 32 beds. Therefore, most large hospitals in Iran are in low and average performance zones of the Pabon Lasso graph. Another study which was conducted in 2004, confirms this theory (46). Studies conducted in Denmark and Portugal emphasized economies of scale and tried to determine the optimal size of hospitals in order to improve hospital performance $(47,48)$. Studies conducted in the USA and the UK show that efficient hospitals have somewhere between 300 and 600 beds (46, 49 ), and that the best performance is seen in hospitals with 200 to 300 beds $(47,50)$. The results of a systematic review done by Giancotti showed that economical and costeffective sizes are attributed to hospitals with 200 to 300 beds, and hospitals with fewer than 200 beds or more than 600 beds are inefficient and uneconomical (51). A study conducted in the Czech Republic also showed that average hospitals, which receive about 10000 patients per year, and hospitals located in big cities, which operate in competitive environments tend to be more efficient (40).

This study showed that most hospitals in the first zone (poor performance) are small and very small hospitals (with fewer than 64 beds) that are located in small cities. Usually, in these sorts of hospitals, due to the lack of specialized wards, defects in the service chain, and low population, few demands are made for in-patient services by the inhabitants of the district. This leads to insufficient utilization of the capacity of these sorts of hospitals, and, consequently, to their inefficiency. Also, it is possible that these hospitals are established in some cities in which in spite of a previously existing hospital with the same quality and characteristics which was sufficiently responding to people's needs, a person or organization has established a new hospital without needs assessment or merely with political or charity purposes in mind $(32,39)$. Findings of a study conducted in Ireland support the policy of closing down small hospitals or reconstructing and extending these hospitals (52).

A high percentage of the hospitals in the third zone of the Pabon Lasso graph (efficient) were public nongovernment, private, and charity hospitals, as well as district hospitals, hospitals with 180 to 250 beds, and hospitals located in cities with populations under 300 thousand people. All of these hospitals are non-teaching hospitals which try to optimally utilize all the available beds through proper management, even if they do not have the minimum number of beds (53). Empirical results show that private and non-profit hospitals are more costeffective and efficient than government hospitals are (54).

Comparing Pabon Lasso graphs of different groups of hospitals in 2013 and 2015 provided the possibility for analyzing the movement of hospitals from efficient zones to inefficient zones. In most groups, a small number of hospitals experienced performance changes, but the changes were quite similar in such a way that in most groups, the number of most efficient and most inefficient hospitals has decreased and the number of averageperformance hospitals has increased. In other words, in the three years of the study (before and after the implementation of the HSEP) the performance difference among hospitals decreased. This is due to the fact that the HSEP, through obligating all government hospitals to perform under similar instructions in receiving and treating patients, has created similar policies and strategies in government hospitals (29).

The short period of time covered in the study is one of the limitations of our study which is due to lake of access to accurate and reliable data of several points of time before and after the HSEP. The data used in this study were collected in for Iran Health Road Map 2026 project in collaboration with all medical universities in the country. Unfortunately, this process has not been done before and has not been repeated since 2015 .

The present study is the first study to assess the performance status of all of the hospitals in a three-year time span. So far, few studies have analyzed the indicators of all the hospitals in a country and the findings of this study can provide evidence about effective parameters on hospital performance. There have been many doubts about the effect of educational performance on hospital efficiency in Iran, but this study showed that based on the Pabon Lasso model, teaching hospitals are significantly less efficient than other hospitals in the country. Since qualitative research is complementary to quantitative research and provides a better understanding of the causes of phenomena (55), it is suggested that qualitative studies be conducted in the future to investigate how various factors affect the 
efficiency of hospitals.

\section{Conclusion}

The present study showed that the HSEP has increased the values of performance indicators in both government and non-government hospitals in Iran. Also, this plan, through creating similar policies and strategies in government hospitals, has caused some most efficient and most inefficient hospitals to become average-performance hospitals. Equal support of government hospitals along with providing financial protection for people against health expenses, has improved the performance indicators of hospitals and reduced the performance differences among them.

\section{Acknowledgment}

We would like to thank the deputy of curative affairs of all provinces across the country.

\section{Conflict of Interests}

The authors declare that they have no competing interests.

\section{References}

1. Prætorius T EK, Hasle P, Nielsen AP. The collaborative hospital: conceptual underpinnings and empirical insights. Downloaded from orbit dtu dk on: Nov 07, 2017. 2014.

2. Jafari M BP, Ibrahimipour H, Dehnavieh R. Attitude of health information system managers and officials of the hospitals regarding the role of information technology in reengineering the business procedures: A qualitative study. HealthMED. 2007;6:208.

3. Khangah HA JA, Imani A, Salimlar S, Derakhshani N, Raef B. Comparing the Health Care System of Iran with Various Countries. Health. Scope. 2017;6(1)

4. Kalantari AR JSM, Mehrolhassani MH, Dehnavieh R. Challenges of implementation: Strategic purchasing in Iran Health Insurance Organization. Int. J. Health Plan. Manag. 2019;34(1):e875-e84.

5. Piroozi B MG, Nouri B, Bolbanabad AM, Safari H. Catastrophic health expenditure after the implementation of health sector evolution plan: a case study in the west of Iran. Int. J. Health Policy Manag. 2016;5(7):417.

6. Moradi G PB, Safari H, Nasab NE, Bolbanabad AM, Yari A. Assessment of the efficiency of hospitals before and after the implementation of health sector evolution plan in Iran based on Pabon Lasso model. Iran. J. Public Health. 2017;46(3):389-95.

7. Marnani AB SJ, Pourmohammadi K, Mostafaie D, Abolhalaj M, Bastani P. Performance assessment indicators: how DEA and Pabon Lasso describe Iranian hospitals' performance. HealthMED. 2012;6(7):791-6.

8. Ajlouni MM, Zyoud A, Jaber B, Shaheen H, Al-Natour M, Anshasi RJ. The relative efficiency of Jordanian public hospitals using data envelopment analysis and Pabon Lasso diagram. Glob. J. Bus. Res. 2013;7(2):59-72.

9. Masoompour SM PP, Farhadi P, Mahdaviazad H. Five-year trend analysis of capacity utilization measures in a teaching hospital 20082012. Shiraz E Medical J. 2015;16(2).

10. Qodoosinejad J DA, Saadati M, Yaghoubi R. Evaluation of the Efficiency of Tabriz Hospitals; Using the Pabon Lasso Model in a 5Year Period. Evid Based Health Policy .Manag. Econ. 2017;1(3):1517.

11. Naghavian M NA, Abdi M, Jahani M. The evaluation of performance indicators in the health care centers of babol university of medical sciences by the Pabon Lasso model (2011-2014). J Babol Univ Med Sci. 2015;17(3):76-82.

12. Mohammadbeig A AZ, hemmati $\mathrm{m}$, rahbar a, mohammad salehi $\mathrm{n}$, eslami moghaddam f. Efficacy analysis using Pabon Lasso Model and comparing with national standards of educational hospitals affiliate to
Qom University of Medical Sciences. Hospital. 2015;14(3):111-8.

13. Kalhor R RF, Rafiei S, Tabatabaee SS, Azmal M, Kalhor L. Performance Analysis of Hospitals Affiliated to Mashhad University of Medical Sciences Using the Pabon Lasso Model: A Six-Year-Trend Study. Biotechnol Health Sci. 2016;3(4):1-6.

14. Hashemian M FM, Moeini poor M, Fattah Hr. Efficiency Evaluation and Comparison of Isfahan Provinces Hospitals Before and after the Reform in Health System using the Pabon Lasso Model (1391-1394). J Ilam Univ Med Sci. 2017;25(3):18;6-200.

15. Ebrahim Z NA, Raeissi P. The Impact of Structure, Process and Output on the Establishment of an Accreditation System in Social Security Hospitals in Tehran. Int. J. Health Stud. 2017;3(3).

16. Asbu E WO, Kirigia J, Zawaira F, Magombo F, Zimpita P. Assessing the efficiency of hospitals in Malawi: An application of the Pabón Lasso technique. Afr Health Monit. 2012;14(1):28-33.

17. Hafidz F, Ensor T, Tubeuf S. Assessing health facility performance in Indonesia using the Pabón-Lasso model and unit cost analysis of health services. Int J Health Plann Manage. 2018 Apr;33(2):e541-56.

18. Nabukeera M, Boerhannoeddin A, RA RN. An evaluation of health centers and hospital efficiency in Kampala capital city authority Uganda; using Pabon Lasso technique. J. Transl. Med. 2015 Jun 30;18(1):12-7.

19. Tripathi CB KR, Sharma RC, Agarwal R. Assessment of performance of services in a tertiary care Neuropsychiatric Institute using Pabon Lasso Model. Asian J. Med. Sci. 2016;7(6):69-74.

20. YİĞIT V. Analysis Of Clinical Bed Utilization Effectiveness In Hospitals With Pabón Lasso Modell. Int. J. Health Manage Strategies Res. 2017;3(1):164-74.

21. Yiğit V, Esen H. Pabon Lasso Modeli ve Veri Zarflama Analizi ile Hastanelerde Performans Ölçümüi Performance Measurement in Hospitals with Pabon Lasso Model and Data Envelopment Analysis. Sdü Sağlık Bilimleri Enstitüsü Dergisi. 2017; Online First 1.

22. Younsi M. Performance of Tunisian public hospitals: A comparative assessment using the Pabón Lasso Model. Int. J. Hosp. Res. 2014;3(4):159-66.

23. Lasso HP. Evaluating hospital performance through simultaneous application of several indicators. 1986.

24. Goshtasbi A VM, Gorjipour R, Samanpour A, Maftoun F, Farzadi F, et al. Assessing hospital performance by the Pabon Lasso Model. Iran. J. Public Health. 2009;38(2):119-24.

25. Ahmadkiadaliri A H-BH, Zarei A. Measuring efficiency of general hospitals in the south of Iran. World Appl. Sci. J. 2011;13(6):1310-6.

26. Naghdi S MT, Tavangar F, Bahrami G, Shahboulaghi M, Ghiasvand $\mathrm{H}$. The barriers to achieve financial protection in Iranian health system: a qualitative study in a developing country. Ethiop. J. Health Sci. 2017;27(5):491-500.

27. Arab-zozani M. Health Sector Ewolution in Iran; A Short Review. Evidence Based Health Policy. Manag. Econ. 2017;1(3):193-7.

28. Mehrolhassani MH, Najafi B, Yazdi Feyzabadi V, Haghdoost A, Abolhallaje M, Ansari M, et al. Total Health Expenditures and proportion of Out-of-Pocket payments in Iranian Provinces; 20082014. Iran. J. Epidemiology. 2017;12(5):1-12.

29. Nabilou B SP, Yusefzadeh H. Performance Assessment Of Health System Reform Plan In The Hospitals Affiliated With Urmia University Of Medical Sciences. J Urmia Nurs Midwifery Fac. 2017;14(11):896-905.

30. Vafaee-Najar A PA, Ebrahimipour H, Dehnavieh R. Study of patient's complaints reported over 36 months at a large public educational specialized center of obstetrics and gynecology. Middle East J Sci Res. 2013;16(1):23-9.

31. Rezaei S RfA, Arab M, Jaafaripooyan e. Effects of the New Health Reform Plan on the Performance Indicators of Hamedan University Hospitals. J. Sch Public Health Public Health Res. Inst. 2016;14(2):51-60.

32. Kavosi Z GS, Almasiankia A. Performance Evaluation In Hospitals Of Lorestan University Of Medical Sciences Using Pabon-Lasso Model. Payavard Salamat. 2013;6(5).

33. Asmild M HB, Birch S. The scale of hospital production in different settings: One size does not fit all. J. Product. Anal. 2013;40(2):197206.

34. Mujasi PN AE, Puig-Junoy J. How efficient are referral hospitals in Uganda? A data envelopment analysis and tobit regression approach. BMC Health Serv. Res. 2016;16(1):230.

35. Nayar P OY, Yu F, Nguyen AT. Benchmarking urban acute care hospitals: efficiency and quality perspectives. Health Care Manage 
Rev. 2013;38(2):137-45.

36. Liu Q ZX, Guo Y, Zhang Y, Wang Y, Li B, et al. The Correlation of Hospital Operational Efficiency and Average Length of Stay in China: A Study Based on Provincial Level Data. J. Biosci. Medicine. 2016;4: 49-55.

37. Farzianpour F EA, Foroushani AR, Ghiasi A. Determining the Technical Efficiency of Hospitals in Tabriz City Using Data Envelopment Analysis for 2013-2014. Glob. J. Health Sci. 2016;9(5):42.

38. Bastani P LF, Moradi M, Ahmadzadeh MS. The Performance Analysis of Teaching Hospitals Affiliated with Shiraz University of Medical Sciences Before and After Health System Reform Plan Using Pabon Lasso Model. J Rafsanjan Univ Med Sci. 2016;15(8):781-92.

39. Davoud A IB, Sadeghi G, Mohammad P, Hossein A, Salarkhah E. Contemporary use of hospital efficiency indicators to evaluate hospital performance using the Pabon Lasso model. European J Buss \& Soci Sci. 2014;3(2):1-8.

40. Votápková J, Št'astná L. Efficiency of Hospitals in the Czech Republic. Prague Economic Papers. 2013;22(4):524-41.

41. Jamison DT BJ, Measham AR, Alleyne G, Claeson M, Evans DB, et al. Disease control priorities in developing countries: The World Bank; 2006.

42. Hekmat SN TS, Haghdoost A-A, Ebrahimipour H, Mehrolhassani $\mathrm{MH}$, R. D. Beneficial and Adverse Effects of the Integration of Medical Education and Health Service in IR. Iran; A Delphi Exercise. J Med Sci. 2014;14(1):21-8.

43. Tiemann O, Schreyögg J. Effects of ownership on hospital efficiency in Germany. Bus Res. 2009;2(2):115-45.

44. Coyne JS RM, Short R, Shultz K, Singh SG. Hospital cost and efficiency: do hospital size and ownership type really matter? J. Healthc. Manag. 2009;54(3):163-76.

45. Kakeman E FA, Dargahi H. Technical Efficiency of Hospitals in Tehran, Iran. Iran. J. Public Health. 2016;45(4):494-502.

46. Wilson P, Carey K. Nonparametric analysis of returns to scale in the US hospital industry. J. Appl. Econom. 2004;19(4):505-24.

47. Azevedo H, Mateus C. Cost effects of hospital mergers in Portugal. Eur. J. Health Econ. 2014;15(9):999-1010.

48. Kristensen T BP, Pedersen KM. Potential gains from hospital mergers in Denmark. Health Care Manag. Sci. 2010;13(4):334-45.

49. Roh C-Y JMM, Jung C. Measuring performance of US nonprofit hospitals: do size and location matter? Public Perform. Manag. Rev. 2010;34(1):22-37.

50. Hefty T. Returns to scale in hospitals: a critical review of recent research. Health Serv. Res. 1969;4(4):267.

51. Giancotti M GA, Mauro M. Efficiency and optimal size of hospitals: Results of a systematic search. PLOS ONE. 2017;12(3):e0174533.

52. McKillop DG GJ, Kerr CA, McCallion G. Efficiency in Northern Ireland hospitals: A non-parametric analysis. Vol XX, No XX, Issue, Year. 1999

53. Nwagbara V, R RR. Rethinking health care commercialization: evidence from Malaysia . Glob. Health. 2015;11(1):44.

54. Herr A. Cost and technical efficiency of German hospitals: does ownership matter? . Health Econ. 2008;17(9):1057-71.

55. Mansoori P, Majdzadeh R, Abdi Z, Rudan I, Chan KY, Aarabi M, Ahmadnezhad E, Ahmadnia S, Akhondzadeh S, Azin A, Azizi F. Setting research priorities to achieve long-term health targets in Iran. J. Glob. Health. 2018 Dec;8(2). 